\title{
Lipid Profile Status In Surgical Menopause
}

\author{
Farhana Kabir $^{1}$, Nasim Jahan ${ }^{2}$, Nayma Sultana ${ }^{3}$, Rezina Akter ${ }^{4}$
}

\begin{abstract}
Background: Dyslipidaemia in both surgical and natural menopausal women is a common health hazard all over the world. Moreover, the surgical menopausal women may have greater chance of this disorder than those of natural menopausal women. Objective: To observe lipid profile level in surgical menopausal women in Bangladesh. Methods: This cross sectional study was carried out in the Department of Physiology, Sir Salimullah Medical College, Dhaka from $1^{\text {st }}$ January 2010 to $31^{\text {st }}$ December 2010. A total number of 90 female subjects were included in this study. They were divided into control and study groups. Among them 6o women were taken as control (30 premenopausal women- group A and 30 natural menopausal women -group B) and 30 were taken as study (surgical menopausal-group C).However, age range of premanopausal women were from 30-35 years, natural menopausal women from 50-60 years and surgical menopausal women from 45-55 years. All the menopausal women were selected from Out Patient Department (OPD) of Gynaecology and Obstetrics of Sir Salimullah Medical College and Mitford Hospital. Premenopausal women were selected by personal contact. Serum lipid profile and serum estrogen levels of all participants were estimated by enzymatic method and by AxSYM method respectively. The statistical analysis was done by using appropriate method as applicable. Results: In this study, mean serum triglyceride (TG) level was significantly $(\mathrm{p}<0.05)$ higher and serum high density lipoprotein cholesterol (HDL-C) level was significantly $(\mathrm{p}<0.001)$ lower in surgical menopausal women than those of natural menopausal women. . Again, mean serum estrogen level was significantly $(\mathrm{p}<0.001)$ lower in surgical menopausal women than that of natural menopausal women. Conclusion: The present study revealed that surgical menopausal women have greater chance of dyslipidaemia than those of natural menopausal women.
\end{abstract}

Key words: Menopause, surgical menopause, dyslipidaemia.

J Bangladesh Soc Physiol. 2011 December; 6(2): 127-133 For Authors Affiliation, see end of text.

http://www.banglajol.info/index.php/JBSP

\section{Introduction}

$\mathbf{M}$ enopause is an event that includes the changes caused by the end of reproductive period and the consequence of these changes in the body ${ }^{1}$. Menopause may occur physiologically or artificially. The natural menopause occurs usually between the ages of 45 to 52 years. Whereas, surgical menopause i,e hysterectomy with

Received February 2011; Accepted November 2011 bilateral ooporectomy is performed due to different pathological causes before natural menopause ${ }^{2}$. Menopause, whether it occurs naturally or surgically, is characterized by the reduced production of hormones by the ovaries ${ }^{3}$.There are major changes in estrogen, progesterone, androgen and gonadotropin levels which may be due to ceassation of ovarian follicular activity ${ }^{4}$. 


\section{Article}

Lipid profile abnormalities in the menopausal women are common health hazard all over the world. There is derangement of lipoproteins profile independent of age ${ }^{5}$. Menopausal women have higher plasma levels of total cholesterol (TC), low density lipoprotein cholesterol (LDLC), very low density lipoprotein cholesterol (VLDL-C) and triglyceride (TG) when compared with premenopausal women ${ }^{6}$.

Hypercholesterolemia is a key factor in the development of atherosclerosis ${ }^{7}$.A number of changes that occur in the lipid profile after menopause are associated with increased risk of atherosclerosis, coronary heart disease and myocardial infarction may be due to lack of estrogen ${ }^{8}$. Ovarian estrogen seems to be inversely related to the development of cardiovascular disease and elevated serum lipid levels ${ }^{9}$.

A stronger relationship was found between cardiovascular disease morbidity, mortality and surgical menopausal women ${ }^{10}$. Some researchers reported that the rate of metabolic syndrome (hypertension, hyperglycemia and dyslipidaemia) was higher in surgical menopausal women than that of natural menopausal women ${ }^{3}$. Again, risk factors for cardiovascular disease morbidity and mortality such as dyslipidaemia, glucose intolerance and hypertension appear more slowly in natural menopausal women ${ }^{10}$. It has also been suggested that estrogen level drops abruptly in women with bilateral oophorectomy whereas gradually in natural menopausal women ${ }^{11}$. Hysterectomy alone can not increase risk of cardiovascular disease, but hysterectomy may lead to subsequent ovarian failure ${ }^{10}$. After the age of 50 years, the risk of myocardial infarction increases among the oophorectomized women, compared with women who retain their ovaries

12 . However, after natural menopause, ovaries continue to produce significant amount of androgens, which are converted to estrogen peripherally ${ }^{13}$.
Lipid Profile in Surgical Menopause

Some investigators observed that hysterectomy with bilateral oophorectomized women had higher level of TG and TC than those of natural menopausal women ${ }^{14}$. Again, surgically menopausal women had higher level of LDL-C than that of natural menopausal women ${ }^{15}$. Recently it has also been observed that HDL level was significantly lower and VLDL level was significantly higher in surgically menopausal women than those of natural menopausal women ${ }^{16}$.

Surgical menopause was found to be strongly associated with postmenopausal syndrome and dyslipidaemia than those of natural menopausal women. Postmenopausal syndrome and its complication in Bangladeshi women are increasing with time. Although recently some studies have been done on dyslipidaemia in menopausal women in our country ${ }^{17}$. But little is known about the risk of lipid profile abnormalities in surgical menopausal women. Therefore, the present study has been undertaken to observe and compare the changes in lipid profile status between the surgical and natural menopausal women in Bangladesh. It is expected that the findings of the study would give a guideline to the physician for early detection and better management of this changes in both types of menopausal women in order to improve their quality of life.

\section{Methods}

This cross sectional study was carried out in the Department of Physiology, Sir Salimullah Medical College, Dhaka from $1^{\text {st }}$ January 2010 to $31^{\text {st }}$ December 2010. A total number of 90 female subjects were included in this study. They were divided into control and study groups. Among them 60 women were taken as control (30 premenopausal women- group A and 30 natural menopausal women -group B) and 30 were taken as study (surgical menopausal-group C). However, age range of premanopausal women were from $30-35$ years, natural menopausal women from 50-60 years and surgical menopausal women 
from 45-55 years. All the menopausal women were selected from Out Patient Department (OPD) of Gynaecology and Obstetrics of Sir Salimullah Medical College and Mitford Hospital. Premenopausal women were selected by personal contact. All the subjects were belonged to lower middle socioeconomic status. Subjects with any acute or chronic disease (hypertension, diabetes mellitus, tuberculosis, and heart disease), suffering from mental disorder, using prescribed medicine or alcohol, and with smoking habit were excluded from the study. The aim, objectives, risk and the procedure of the study were explained in details to the subjects and their written informed consents were taken. Ethical permission was taken from the Institutional Ethics committee (IEC) of Sir Salimullah Medical College. Detailed family history and medical history of the subjects were also taken. Then their general information and data were recorded in the prefixed questionnaire. With all aseptic precautions, five (5) $\mathrm{ml}$ of venous blood was drawn from median cubital vein by sterile disposable syringe. Serum lipid profile of all participants were estimated by enzymatic method in the laboratory of Physiology Department, Sir Salimullah Medical College, Mitford 18,19. Serum estrogen level ${ }^{20}$ of menopausal women was estimated by AxSYM method in the Department of Biochemistry, BSMMU, Dhaka

Statistical analysis was done by using Statistical Package of Social Service (SPSS) for windows version 15. Data were expressed as mean $\pm \mathrm{SD}$ ANOVA, Bonferroni test, Independent sample ' $t$ ' test, Chi- square $\left(\chi^{2}\right)$ test and Fisher's exact test were used as the test of significance as applicable.

\section{Results}

The mean serum estrogen level was significantly $(p<0.001)$ lower in surgical menopausal women
(Group C) than that of natural menopausal women (Group B) (Figure 1).

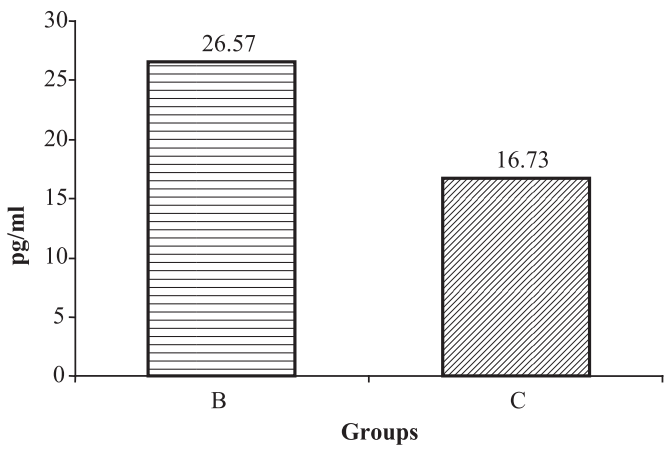

Group B: Natural menopausal women. (Control) Group C: Surgical menopausal women. (Study)

Figure1: Mean Serum Estrogen levels in menopausal women $(n=60)$

The mean TC, LDL-C and TG levels were significantly $(p<0.001)$ higher whereas the mean HDL-C level was significantly $(\mathrm{p}<0.001)$ lower in surgical menopausal women (Group C) and natural menopausal women (Group B) than those of premanopausal women (Group A). Again, the mean TG level was significantly $(\mathrm{p}<0.05)$ higher whereas, mean TC and LDL-C levels were higher in surgical menopausal women but not significant (Group C) in comparison to those of natural menopausal women (Group B). Furthermore, mean HDL-C level was significantly $(\mathrm{p}<0.001)$ lower in surgical menopausal women (Group C) than that of natural menopausal women (Group B). (Table I)

Moreover, the percentage of the subject with abnormal lipid profile was higher in surgical menopausal women than that of natural menopausal women but the difference was not statistically significant. None of the subjects of premenopausal women had abnormal lipid profile status (Figure 2). 
Table I: Serum lipid profile in different groups $(\mathrm{n}=90)$

\begin{tabular}{lccccc}
\hline Groups & $\mathrm{n}$ & $\mathrm{TC}(\mathrm{mg} / \mathrm{dl})$ & $\mathrm{HDL}(\mathrm{mg} / \mathrm{dl})$ & $\mathrm{LDL}(\mathrm{mg} / \mathrm{dl})$ & $\mathrm{TG}(\mathrm{mg} / \mathrm{dl})$ \\
\hline A & 30 & $137.17 \pm 7.95$ & $39.53 \pm 2.56$ & $78.37 \pm 9.08$ & $96.33 \pm 12.87$ \\
& & $(120.0-150.0)$ & $(37.0-48.0)$ & $(62.0-98.0)$ & $(70.0-125.0)$ \\
B & $206.13 \pm 23.06$ & $32.70 \pm 3.22$ & $142.53 \pm 22.43$ & $154.50 \pm 23.57$ \\
& $(166.0-256.0)$ & $(26.0-40.0)$ & $(101.0-192.0)$ & $(114.0-216.0)$ \\
C & $219.60 \pm 37.75$ & $27.63 \pm 2.66$ & $157.23 \pm 33.47$ & $173.67 \pm 35.10$ \\
& 30 & $(150.0-286.0)$ & $(23.0-34.0)$ & $(93.6-221.0)$ & $(103.0-241.0)$ \\
\hline Statistical analysis & & & & \\
\hline Groups & & $\mathrm{TC}$ & $\mathrm{HDL}$ & $\mathrm{LDL}$ & $\mathrm{TG}$ \\
& & $(\mathrm{p}$ value $)$ & $(\mathrm{p}$ value $)$ & $(\mathrm{p}$ value $)$ & $(\mathrm{p}$ value $)$ \\
\hline A vs B vs C & $0.000^{* * *}$ & $0.000^{* * *}$ & $0.000^{* * *}$ & $0.000^{* * *}$ \\
A vs B & $0.000^{* * *}$ & $0.000^{* * *}$ & $0.000^{* * *}$ & $0.000^{* * *}$ \\
A vs C & $0.000^{* * *}$ & $0.000^{* * *}$ & $0.000^{* * *}$ & $0.000^{* * *}$ \\
B vs C & $0.143^{\mathrm{ns}}$ & $0.000^{* * *}$ & $0.057^{\mathrm{ns}}$ & $0.014^{*}$ \\
\hline
\end{tabular}

Data are expressed as Mean \pm SD. For statistical analysis One way ANOVA was perfomed for comparison among the groups and then Bonferroni test was done to compare between two groups.

Figures in parentheses indicate ranges

Group A: Apparently healthy premenopausal women. (Baseline control), Group B: Natural menopausal women. (Control), Group C: Surgical menopausal women. (Study)

$*=$ Significant at $\mathrm{p}<0.05, * * *=$ Significant at $\mathrm{p}<0.001$, ns $=$ Not significant, $\mathrm{n}=$ total number of subjects

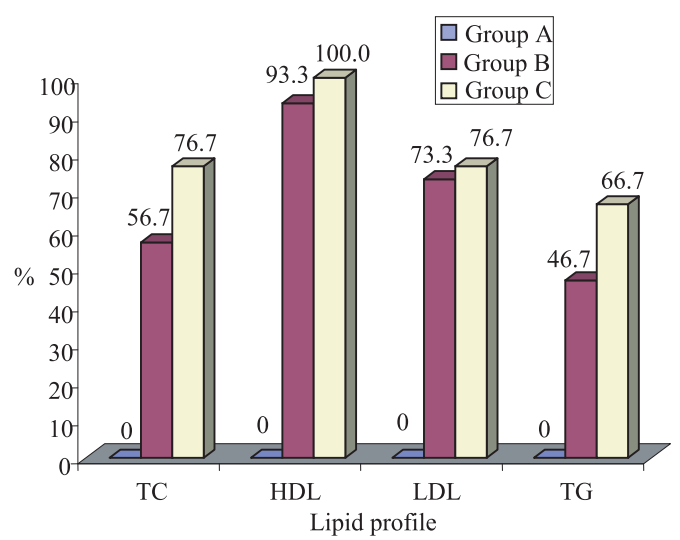

Figure 2: Distribution of the study subjects by abnormal lipid profile status $(\mathrm{n}=90)$

\section{Discussion}

In the present study, mean TC, LDL-C and TG levels were significantly higher whereas the mean HDL-C level was significantly lower in surgical and natural menopausal women than those of premenopausal women. These findings are in agreement with those of researchers of different countries $^{7,17,21}$.

Moreover, mean TG level was significantly higher whereas, mean TC and LDL-C levels were nonsignificantly higher in surgical menopausal women in comparison to those of natural menopausal women. Whereas, mean HDL-C level was significantly lower in surgical menopausal 
women than that of natural menopausal women. Similar observations were also made by other research workers $3,15,16$.

Again, in this study, significantly lower serum estrogen level was found in surgical menopausal women than that of natural menopausal women. Similar finding was also made by other research workers ${ }^{22}$. On the contrary, some researchers observed higher level of serum estrogen level in surgical menopausal women than that of natural menopausal women ${ }^{23}$. This discrepancy may be due to higher age range of postmenopausal women in that study in comparison to our study group.

Small amount of estrogen and androgens are produced by ovary in natural menopausal women 13 . Whereas, after bilateral oophorectomy, serum estrogen and testosterone levels decreased and follicle stimulating hormone rises suddenly ${ }^{4}$.

Some investigators suggested that a significant amount of estrogen in menopausal women come from peripheral conversion of androstenedione in adipose tissue. Thus the conversion is greater in obese women ${ }^{13}$. Therefore, after surgical removal of ovary, there is significant decrease in androgen production resulting decrease in estrogen level ${ }^{4}$.

Gradual decrease of serum estrogen level especially after the age of 45 years may be responsible for some features of metabolic syndrome such as abdominal obesity, insulin resistance, dyslipidemia and hypertension ${ }^{24}$. It has been suggested that, estrogen deficiency after menopause causes insulin resistance which in turn causes increased circulatory level of TG 25 . In addition to this insulin resistance also causes increased activity of hormone sensitive lipase resulting in increased level of free fatty acid and accumulation of abdominal fat ${ }^{9}$.

Again, estrogen increases the number of LDL receptors in the liver and therefore increases the uptake of LDL-C from blood into liver ${ }^{26}$. Thus the serum level of this lipoprotein decreases. Furthermore, estrogen stimulates Apo- $\mathrm{A}_{1}$ synthesis in liver and small intestine resulting in an increase in HDL-C level 27 . Thus estrogen deficiency in menopausal women may lead to increase serum LDL-C and decrease HDL-C level.

Serum estrogen level decreases abruptly after hysterectomy with bilateral oophorectomized women. This acute withdrawl of the hormone in surgical menopausal women may cause more changes in lipid profile level than those of natural menopausal women ${ }^{16}$.

In the present study, impairment of lipid profile status was observed in both natural and surgical menopausal women. The higher value of TC, LDL$\mathrm{C}, \mathrm{TG}$ and lower value of HDL-C observed in menopausal women of the present series are most likely due to estrogen deficiency as the measured value of them were lower. Again, in this study, significantly higher value of TG and significantly lower value of HDL-C in surgical menopausal women indicating that dyslipidaemia was more pronounced in this group of women compared to that of natural menopausal women. This is further supported by involvement of more number of subjects with abnormal lipid profile in surgical menopausal group which may be due to their lower level of serum estrogen.

\section{Conclusion}

From the present study, it can be concluded that dyslipidaemia was more pronounced in surgical menopausal women than those of natural menopausal women. Impairment of lipid profile status was observed by higher level of TC, LDLC, TG and lower level of HDL-C in surgical menopausal women in comparison to those of natural menopausal women. All these changes may be due to their lower level of serum estrogen.

\section{Acknowledgement}

Authors of this study are thankful to the authority of Department of Gynaecology and Obstetrics of Sir Salimullah Medical College and Mitford Hospital for their nice cooperation during sample collection. The authors acknowledge the partial financial support from the research grant of DGHS 
of Bangladesh. And finally author is very much thankful to the subjects who have actively participated.

\section{Authors Affiliation}

1. *Farhana Kabir. E-mail: fkab1r@hotmail.com

2. Nasim Jahan, Professor and Head, Department of Physiology, Sir Salimullah Medical College, Dhaka. E-mail: prof.dr.nasimjahan@gmail.com

3. Nayma Sultana, Associate Professor, Department of Physiology, Sir Salimullah Medical College, Dhaka. Email;nayma_sultana@yahoo.com

4. Rezina Akter, Department of Physiology, Sir Salimullah Medical College, Dhaka.

*for correspondence

\section{References}

1. Seckin NC, Sener AB, Turhan NO, Gokmen O, Orhan E, Bulgurlu H. The menopausal age, related factors and climacteric symptoms in Turkish women. Maturitas 1998; 30: 37-40.

2. Speroff L, Glass RH, Kase NG. Clinical Gynecologic Endocrinology and Infertility. $5^{\text {th }}$ ed. Philadelphia: Williams \& Wilkins; 1994. p121-164.

3. Ozdemir S, Celik C, Gorkemili H, Kiyici A, Kaya, B. Compared effects of surgical and natural menopause on climacteric symptoms, osteoporosis and metabolic syndrome. Int $\mathrm{J}$ Gynecol and Obst 2009; 106: 57-61.

4. Davison SL, Bell R, Donath S, Montalto JG, Davis SR. Androgen levels in adult females: changes with age, menopause and oophorectomy. J Clin Endocrinol Metab 2005; 90: 3847-3853.

5. Bales AC. In search of lipid balance in older women; New studies raise questions about what works best. Postgrad. Med 2000; 108(7): 57-72.

6. Matthan NR, Jalbert SM, Fava SL, Dolnikowski GG, Welty FK, Barrett HR, Schaefer EJ, Lichtenstein AH. TRL, IDL and LDL Apolipoprotein B - 100 and HDL Apolipoprotein A - I Kinetics as a function of age and menopausal status. Arteriosclerosis, Thrombosis and Vascular Biology 2005; 25: 1691.

7. Igweh JC, Nwagha IU, Okaro JM. The effects of menopause on the serum lipid profile of normal females of south east Nigeria. Nigerian Journal of Physiological Sciences 2005; 20(1-2): 48-53.

8. Barrett-Connor E, Bush TL. Estrogen and coronary heart disease in women. JAMA 1991; 265(4): 18611867.
9. Mathews KA, Meilahn E, Kuller LH, Kelsey SF, Gaggiula A, Wing RR. Menopause and risk factors for coronary heart disease. N Eng J Med 1989; 321(10): 641-646.

10. Stampfer MJ, Colditz GA, Willett WC 1990. Menopause and heart disease: a review. Ann NY Acad Sci 1990; 592: 286-294.

11. Howard BV, Kuller L, Langer R, Manson JE, Allen C, Assaf A, Cochrane BB, Larson JC, Lasser N, Rainford M, Van-Horn L, Stefanick ML, Trevisan M. Risk of cardiovascular disease by hysterectomy status, with and without oophorectomy. Circulation 2005; 111:1462-1470.

12. Falkeborn M, Schairer C, Naessen T, Persson I. Risk of myocardial infarction after oophorectomy and hysterectomy. J Clin Epidemol 2000; 53: 832837.

13. Fogle R, Stanczyk F, Zhang X, Paulson R. Ovarian androgen production in postmenopausal women. $\mathrm{J}$ Clin Endocrinol Metab 2007; 92(8): 3040-3043.

14. Kritz-Silverstein D, Barrett-Connor E, Wingard DL. Hysterectomy, oophorectomy and heart disease risk factors in older women. Am Journal Pub Health 1997; 87(4): 676-680.

15. Zhang Y, Lee ET, Cowan LD, North KE, Wild RA, Howard BV. Hysterectomy prevalence and cardiovascular disease risk factors in American Indian women. Maturitas 2005; 52: 328-336.

16. Tuna V, Alkis I, Safiye As, Imamoglu N, Bayram N, Ismet TA. Variations in blood lipid profile, thrombotic system, arterial elasticity and psychosexual parameters in the cases of surgical and natural menopause. Australian and New Zealand Journal of Obstetrics and Gynaecology 2010; 50: 194-199.

17. Ferdous T. Effects of physical exercise and hormone replacement therapy on lipid profile status in postmenopausal women [M. Phil thesis]. [Dhaka]: University of Dhaka; 2010.p20-60.

18. Naito HK, Kaplan A. Quantitative determination of cholesterol. Clin Chem 1984; 5: 1194-1206.

19. Buccolo G. Quantitative determination of serum triglycerides by use of enzymes. Clin Chem 1973; 19(5): 476-482.

20. AxSYM Estradiol assay, Abbott Laboratories. Diagnostic division 2004: 1-8.

21. Suda Y, Ohta H, Makita K, Takamatsu K, Horiguchi F, Nozawa S. Influence of bilateral oophorectomy upon lipid metabolism. Maturitas 1998; 29: 147154 . 
22. Yasui T, Uemura H, Umino Y, Takikawa M, Saito S, Kuwahara A, Matsuzaki T, Maegawa M, Furumoto H, Miura M, Irahara M. Serum estrogen level after hormone replacement therapy and body mass index in postmenopausal and bilaterally ovariectomized women. Maturitas 2005; 50: 19-29.

23. Wakatsuki A, Sagara Y. Lipoprotein metabolism in postmenopausal and oophorectomized women. Obstel Gynecol 1995; 85: 523-528.

24. Creatsas G, Christodoulakos G, Lambrinoudaki I. Cardoivascular disease: Screening and management of the asymptomatic high risk postmenopausal women. Maturitas 2005; 52S: S32-S37.

25. Mahabir S, Baer DJ, Johson LL, Hartman TJ, Dorgan JF, Cambell WS, Lenience BA, Taylor PR.
Usefulness of body mass index as a sufficient adiposity measurement for hormone concentration associations in postmenopausal women. Cancer Epidemiology Biomarks and Prevention 2006; 15: 2502-2507.

26. Saltiki K, Alevizaki M. Coronary heart disease in postmenopausal women; the role of endogenous estrogens and their receptors. Hormones 2007; 6(1): 9-24

27. Honju H, Tanaka K, Urabe M, Naitoh K, Ogino Y, Yamamoto T, Okada H. Menopause and hyperlipidaemia: pravastatin lowers lipid levels without decreasing endogenous estrogen. Clin Ther 1992; 14: 699-707. 